\title{
Behind the Clouds: Teaching and Researching Anthropology in Tertiary Institutions in Nigeria
}

\author{
Edlyne E. A nugwom*
}

\begin{abstract}
The paper focuses on teaching and researching of anthropology as a culture centred discipline in Nigeria. It notes that in spite of decades of emergence as a university discipline, anthropology has not been able to break through the negative clouds of colonialism and subjugation to its twin discipline, sociology. Factors responsible for the poor state of teaching and research in anthropology in Nigeria include institutional and structural incapacities and limitations, a curriculum that fails to address both the aspirations of the students and the role of the discipline in national development as well as the inability of the anthropologists themselves to rise up to the dynamic challenges of contemporary Nigerian society. In view of the foregoing, there is need for a serious rethinking and fundamental restructuring of the discipline focusing essentially on the curriculum, professionalism and development values of the discipline. It is only through the above that teaching and researching in anthropology would be more fruitful to both theoretical and practical concerns as an authentic narrative and imagery of African cultural realities.
\end{abstract}

\section{Résumé}

Cette communication est focalisée sur l'enseignement et la recherche de l'Anthropologie comme une discipline centrée sur la culture au Nigéria. Bien qu'on note son émergence depuis des décénnies comme une discipline universitaire, l'Anthropologie, avec sa sœur jumelle qu'est la sociologie, n'a pas pu percer la vision négative du colonialisme et de la conquête. Les facteurs à la base du mauvais état de l'enseignement et de la recherche en Anthropologie au Nigéria, ont trait à une incapacité institutionnelle et structurelle, des limites et

* Department of Sociology/Anthropology,University of Nigeria, Nsukka, Nigeria. Email: edlyneeze@yahoo.com. 
un curriculum qui ne parviennent pas à promouvoir les aspirations ou les attentes des étudiants et le rôle de la discipline dans le développement national aussi, et l'incapacité des anthropologues euxmêmes à faire face aux défis dynamiques de la société contemporaine au Nigéria. Dans le processus évolutif, il ya un besoin sérieux de repenser et de restructurer fondamentalement la discipline tout en se focalisant essentiellement sur le programme d'étude, le professionnalisme et le développement de valeur de la discipline. Ainsi, l'enseignement et la recherche en Anthropologie pourraient être plus fructueux à la fois sur le plan théorique et pratique tout en étant une narrative authentique qui reflète la réalité culturelle africaine.

\section{Introduction}

The teaching and researching of anthropology, ${ }^{1}$ as a social science discipline in Nigeria has been affected both by the increasing rot in the public university system, especially in the last two decades and the development constraints which have imposed economic relevance on courses taught in Nigerian universities. The first problem is general to education in Nigeria's public universities which have grossly declined as a result of neglect and a wrong footed privatisation of tertiary education in $\mathrm{Ni}$ geria, which is part of the liberalisation efforts of the government in the last two decades. The second problem, arising from an underdeveloped economy, which equates the relevance of any discipline to its market value or ability to generate jobs for those who studied the discipline, has had a negative impact on the growth of anthropology as a discipline. In this case, the average university student in Nigeria cannot easily relate anthropology to the overarching need for employment on graduation. Thus, anthropology is often characterised as a discipline without employment or job prospects in the Nigerian economy. This dire picture has not been improved or helped by a stagnant curriculum and teaching approaches that are inured to both the dynamism of knowledge and society. While institutional and economic constraints have undermined research and curriculum development in anthropology, anthropologists in Nigeria, with a few notable exceptions, have failed to live up to the challenges of modern scholarship. These factors may have influenced the standing of anthropology in today's Nigeria.

But equally bestriding the above issues is the well known old dilemma of anthropology as a colonial discipline. In this case, the emergence and prominence of anthropology has been linked strongly to the exigencies of the colonial enterprise. Precisely, anthropology emerged clearly in the colonial contact period as an intellectual exercise to legitimise and/or justify colonialism. It is in this light that anthropology has 
been perceived as an effort to endorse the subsumed superiority of the colonisers in Africa. Therefore, while anthropology is without doubt beyond this parochial stamp, it was all the same utilised in furthering the imperial aims of the colonial powers. Hence, given the general abuse and misuse of anthropology by colonialism, there can be no argument about the need for a constant re-interrogation of the discipline. The obvious hijack and misuse of the discipline by the colonial enterprise in Africa (see, Prah, 1992; Diop, 1992; Akiwowo, 1976 etc) makes such re-examination of the history, content and relevance of social anthropology worthwhile.

Therefore, the importance of an examination of teaching and research in anthropology cannot be over-emphasised at this point in the development of the discipline in Nigeria. As has been argued, this is invaluable in order to raise the status of the discipline (Jegede, 2000). Hence, the paper attempts equally to highlight the various factors impacting on the growth, acceptance and relevance of the discipline in Nigeria as well as identifying constraints to the teaching and researching of anthropology as a university discipline in order to arrive at ways of moving the study of anthropology forward in Nigeria.

\section{From Origin to Perception: The Roots of Anthropology and the African View}

One of the greatest pioneers of social anthropology was Lewis H. Morgan (1818-1881) who studied the indigenous people of Ho-de-no-sau-nee or the Iroquois in his home state of New York, USA. Morgan was a lawyer who became fascinated with the ways of life of the indigenous Iroquois. But the influence of Morgan and other non-professional anthropologists like him in the ascendancy of the discipline can be seen equally as part of the cause of the cynicism enveloping the discipline in developing societies of the world. The involvement of non-professionals in the development of the discipline has ultimately mired the scientific claim and professionalism of anthropology in some controversy. In the views of Goldthorpe (1985:30), "most of the early observations in social anthropology were indeed the work of people like Morgan who were not trained full-time scientists". These early anthropologists included early voyagers, itinerant merchants, missionaries, seamen, colonial administrators and others of their ilk who were courageous enough to exploit other lands or expand the frontiers of human interaction. In the case of Africa, anthropology came in the guise of the colonial enterprise.

As a matter of fact, the first generation of anthropologists in Africa were either colonial officers or those strongly linked to the colonising 
powers. This fact gave anthropology the unenviable toga of a quasi scientific narration aimed at legitimising the colonial enterprise. Without doubt, the initial anthropology of Africa was stimulated equally by curiosity and the need to understand the way of life of the indigenous Africans in order to facilitate the colonial project (see, Anugwom, 1999). Little wonder, some of these early anthropological forays were funded either by the colonial overlords or missionary and business interests from Europe. Therefore, in Nigeria, as is the case in some other parts of Africa, anthropology represented the white man's efforts to understand "strange" culture and social practices of Africans who were then labelled either primitive or barbaric.

Therefore, anthropology, during the colonial period through independence, did remain as a "gateway" by which African cultures were understudied and replaced by Western ones. It was mostly serving colonial empire-builders" (Jegede, 2000:11). However, there is need to make a distinction between the real early anthropologists in Africa who were men of science who pioneered the use of the qualitative approach and the early non-professional or government anthropologists who were not driven by the methodological or scientific rigours of the discipline. But even within the ranks of the pioneering anthropologists, interest was often spurred by the esoteric and uniqueness of strange and distant peoples. As a result, "anthropologists are generally envisioned as travelling to little known corners of the world to study exotic people or as digging deep into the earth to uncover the fossil remains or tools and pots of people who lived long ago" (Ember and Ember, 1977:4). It was this scenario that fostered the Eurocentric conceptualisation of anthropology as the study or concern with primitive people and societies. A view that is nowadays debunked as pejorative and limited.

In spite of the above facts, there were some scientific anthropologists who came after the first journeymen anthropologists and carried out insightful and classical studies of African societies. Among these early but "second generation anthropologists", not necessarily fettered by colonialism who worked in Africa were I. Schepera, Evans Pritchard, Meyer Fortes, Lucy Mair, J. J. Maquet, L.A Fallers, and of course Radcliffe-Brown (who did a very insightful work on African systems of kinship and marriage) among others. Pioneering pre-colonial scientific anthropologists in Nigeria include people like Simon Ottenberg, C. K. Meek, M. M. Green, G. T. Basden, G. I. Jones etc who studied the Igbo of South-eastern Nigeria; D. Forde, M. G. Smith, S, Nadel who studied the Zazzau and Nupe of Northern Nigeria; P. J. Bohannan who studied the Tiv of the Middle belt 
Nigeria; P. Morton-Williams who studied the Yoruba of South-western Nigeria. The above list is without doubt not exhaustive but shows quite a good number of the pioneering anthropologists in Nigeria. Without prejudice to the works of the above scholars, the colonial administration's interest in anthropology in Nigeria and elsewhere in Africa, coupled with emergence of some ad-hoc or emergency anthropologists at the behest of the colonial enterprise as the first on the stage, did a lot of damage to the credentials of the discipline a science.

According to Mafeje (1996), the first generation of British anthropologists in Africa, by virtue of their background, enjoyed as much power as the colonial administrators who were their collaborators in developing what was labelled applied anthropology. At the centre of the colonial brand of anthropology was an adoption of a British model which gauged other cultures in relation to that of Britain. In this sense, the British cultural pattern, representing modernity and therefore modernization, was basically conforming to British or Western culture. Hence, colonised people, whose cultures were drastically different from that of the British, were often seen as backward and primitive people who ought to be grateful to the liberating influence of colonial rule. This pejorative approach was by no means limited to anthropology, since it reared its head even in the discipline of political science and equally in such an advanced discipline like economics where the backward sloping curve of labour supply was seen as representing the African labour force attitude to increasing wages.

Be that as it may, the above origin of anthropology (unlike other disciplines like political science and economics that quickly shed the ugly toga of colonialism), which affected its legitimacy and professional claim in Nigeria, did not just end in the domain of popular imagery, but spread to academic circles where anthropology came to be seen by African scholars as an attempt to largely mirror the advent of a worldwide recognition of the perceived backward peoples of the world. This viewpoint bred a certain suspicion of the real motives of anthropology as a discipline, a suspicion not helped by the fact that most of the early anthropologists were white fellows. This discomfort of scholars of Africa with anthropology was not equally ameliorated by the claim of the discipline to focus on the physical, socio-cultural and linguistic aspects of human society. Such a curious mix and match was perceived by scholars from Africa as underlining or emanating from the conceptualization of African societies as simple societies at a rudimentary level of development and with no significant social complexity. This picture of Africa logically ran antithetical to the liberalising efforts from the clutches of colonialism 
and ironically supported the 'civilising mission' claim of the colonial enterprise. Therefore, anthropology, at the early stage, often elicited resistance rather than embrace from indigenous scholars.

Interestingly, the decline of anthropology started with the dismantling of colonial rule. In the face of independence, anthropology which had provided justification for colonialism or what Levi-Strauss (1966 in Jegede, 2000) termed participation in the appalling process of domination upon which colonialism was established, sought to make a volteface particularly as it became the subject of hostility and disdain from Africans. However in the bid to do this, anthropologists went into overdrive and in the views of Mafeje (1996) responded to the new situation by becoming anti-colonial, denounced structural functionalism and avoided the previous fascination with tribal studies and focused on thematic concerns. Even though, as Otite (1997) rightly argues anthropology historically predated colonialism, such historical chronology does not sufficiently debunk the prominence of the discipline during colonialism and its misuse and abuse in that period. Actually it is still arguable that anthropology, much like christianity, may have been part of efforts to set the stage for eventual colonialism in Africa. Hence, anthropology in addition to being used by the ad-hoc anthropologists of the colonial era to denigrate the African peoples and cultures then, was equally the source of the 'scientific' justification of the role of the colonial overlords in the continent.

Anthropology, whether now conceived as reflecting a purely sociocultural concern (the overwhelming model in Nigerian tertiary institutions) or as still a holistic focus on the human society, has gone beyond these original crises of legitimacy even though these issues still dog both the development and acceptance of the discipline in Nigeria. Basically the inability of a lot of people, including policy makers and academic administrators, to relate to the needs and values of the discipline in modern Nigeria derives largely from the above. In summary, "anthropology had an origin in the activities of missionaries, travellers and colonial administrators geared Western ends and perpetuating domination. This created a sort of predatory alliance between colonialism and anthropology, since they both arrived with more or less the same motive of exploitation and the imposition of alien cultures on the peoples of Africa" (Anugwom, 2000:40). Given this scenario, anthropology became a counter-narrative especially for the first generation of African scholars who were in Diaspora and saw the need for a deconstruction of the interest sponsored anthropology of Africa created by Westerners. The forays of 
these Africans in Diaspora into presenting what may pass as authentic representation of the African lifestyle and worldview was the genesis of the African anthropology.

\section{The Journey through Time}

The first attempt at studying (teaching) anthropology as a social science and culture related discipline in Nigeria occurred with the establishment of the University of Nigeria Nsukka in 1960. The department of Sociology/Anthropology was one of the first departments established in the university and also took off in 1960. This is in spite of the fact that the University College Ibadan (now University of Ibadan) established in 1948 offers a course in anthropology, but rather as a science discipline with emphasis on physical anthropology and later introduced cultural anthropology as a course under the Faculty of Arts and Humanities.

In spite of the above, formal anthropology in Nigeria, just like the case in most of Africa, is devoid of what may be termed an enviable history. This has to do with its entry on the heels of the colonial project. Actually, this single fact partly explains why African anthropology had a long history of obscurity, since it was seen mainly as playing an ancillary role in the colonial era and identifiable with colonialism (see, CODESRIA Bulletin, 1992). However, in the case of Nigeria, anthropology is yet to emerge from the clouds of origin and, more often than not, play an ancillary role to sociology in most tertiary institutions in the country where both are situated in the same academic department. ${ }^{2}$

The plight of anthropology in this regard has not been helped by the glaring inability of Nigerian anthropologists to adequately fill the void left by the departure of the first generation of Western anthropologists. It is a fact that half of what still passes for quality anthropological work in Nigeria even till date is mainly carried out by non-Nigerians. Thus, while these foreign anthropologists or Africanists keep up a stream of anthropological literature in both journals and books, such knowledge production hardly affects the teaching of the discipline in Nigeria's tertiary institutions. Against the above, the teaching and researching of anthropology in Nigeria's tertiary institutions have moved on at a slow pace $^{3}$ despite the increase in the number of universities over the years. Such increase in number of universities offering the course has not liberated it from the shadows of sociology as it still comes a poor second as the table below shows: 
Table 1: Universities Offering BSc Programmes in Anthropology in Nigeria

\begin{tabular}{ll}
\hline University & Academic Department \\
\hline University of Nigeria, Nsukka & Sociology/Anthropology \\
University of Benin & Sociology/Anthropology \\
Obafemi Awolowo University & Sociology/Anthropology \\
University of Maiduguri & Sociology/Anthropology \\
Nnamdi Azikiwe University & Sociology/Anthropology \\
Benue State University & Sociology/Anthropology \\
Ebonyi State University & Sociology/Anthropology \\
University of Ibadan* & Cultural Anthropology \\
Benson Idahosa University & Sociology/Anthropology \\
Igbinedion University & Sociology/Anthropology \\
\hline
\end{tabular}

Source: Joint Admission and Matriculation Board (JAMB) UME/DE Brochure, 2007/2008 Academic Session.

* Ibadan's cultural anthropology is relatively new and is under the faculty of Arts. The university has a more established biological (physical) anthropology discipline under its biological science programme.

The above table portrays one strong structural constraint which has defined and structured the growth of the discipline of anthropology over the years in Nigeria. This scenario more or less subjects anthropology to a second fiddle role play in relation to sociology. Thus, at the undergraduate level Nigeria produces students who have what may be called combined degrees in both sociology and anthropology, but who are more inclined towards sociology than anthropology since over eighty percent of the courses and academic staff in such combined departments belong to sociology.

\section{Responding to Needs: Curriculum Development and Teaching}

One of the strongest factors hindering the growth of the discipline of anthropology in Nigeria, and by implication in most of the continent, is the over-reliance of the discipline still on methodologies, curricula and research orientations which were developed by Western scholars and are more critically dominated by Western models, ideals and imageries. While this weakness is by no means peculiar to anthropology (but may rather apply to social sciences as a whole), it has produced a scenario 
where the study of African societies by Africans have given rise to outcomes that are neither rooted in nor structured by the African reality. In other words, while we have generated data or information about African societies, our paradigms of explanation, meanings and interpretations have been overtly influenced by Western ideals and perspectives.

The above may be partly a product of the fact that there is overwhelming reliance on Western produced literature and the massive influence of the first generation of anthropologists in African social sciences who were largely Westerners. Be that as it may, the ability to shake off the above Western shroud on the discipline in Africa cannot be overemphasised particularly in view of the fact that this has limited the perceived relevance of the discipline to authentic African problems. The title of courses offered in the discipline are perhaps a good illustration of the fact that anthropology offered in most of African tertiary institutions has little connection to the African reality and contemporary problems that can be meaningfully mediated by a culture based discipline.

Table 2: Anthropology Courses Offered at the BSc Degree Level at the University of Nigeria Nsukka*

\begin{tabular}{ccl} 
S/N & Course Code & \multicolumn{1}{c}{ Course Title } \\
\hline 1. & Anth. 102 & Introduction to Anthropology \\
2. & Anth. 121 & Language in Society and Culture \\
3. & Anth. 201 & History of Anthropological Thought \\
4. & Anth. 212 & African Social Institutions \\
5. & Anth. 213 & Economic Anthropology \\
6. & Anth. 214 & Symbolic Anthropology \\
7. & Anth. 303 & Nigerian Peoples and Culture \\
8. & Anth. 313 & Anthropology of Present Society \\
9. & Anth. 321 & African Religious System \\
10. & Anth. 327 & Traditional Legal Systems \\
11. & Anth. 421 & Race and Ethnic Relations \\
12. & Anth. 423 & Urban Sociology and Anthropology \\
13. & Anth. 412 & Culture and Communication \\
14. & Anth. 411 & Comparative African Social Institutions \\
\hline
\end{tabular}

Source: Undergraduate Hand Book, Department of Sociology/ Anthropology, University of Nigeria, Nsukka. 
* Even though this was taken from the University of Nigeria, we see it as typical and representative of what exists in the other universities offering anthropology in conjunction with sociology at the undergraduate level.

Incidentally, the above table contains the extent of anthropology the student is exposed to in a four year degree programme. But more insightful here is that about half of the above courses come under electives in which case students are free to choose them or opt for some other electives within the faculty. Moreover, those designated as electives like economic anthropology, African religious systems are those with significant bearing on today's contemporary realities. Equally interesting is that these courses show the considerable confusion and prevarication which dog the teaching and researching anthropology. For instance, why would one have urban sociology and anthropology rather than urban anthropology as a course? Also what is the description of the course on Anthropology of present society? Granted there may be something like this, can it be justifiably captured in a one semester two unit course, and is that not like a self indictment that all other courses focus on anthropology of the past society? Be that as it may, only God knows what it is, but it seems like a belated and un-thoughtful attempt to take anthropology beyond the nether years where the curriculum has placed it. The summary here is that these courses are neither adequate nor representative of what anthropology should be today. This may be a source of the inability of a lot of Nigerian students to perceive the relevance of the discipline to their personal and group aspirations as Africans.

Hence, anthropology teaching and research in Nigeria must go beyond a mere rehash of classical literature and viewpoints and a stubborn insistence on the value of knowledge for knowledge sake. It should aspire towards catching-up with both the development needs of the country and the aspirations of its students and teachers in a dynamic and challenging world. Therefore, one aligns with the sentiments of one of the foremost modern Anthropologists in Nigeria, Onigu Otite that, "I suggest a change, something more fundamental and total than mere revisionist anthropology, on the basis of which African Anthropology of African societies may be attempted. This Anthropology must have a sound theoretical base for a utilitarian role in solving practical and ideological problems of Africa" (Otite, 1997:4).

Therefore, in the drawing up of a curriculum for anthropology in Nigeria, the overriding emphasis on the classical issues or themes in 
anthropology should be reduced in order to create room for the introduction and integration of new concerns growing out of the demands of today's society and the need to make anthropology relevant to contemporary problems and situations. Perhaps a way of doing the above has been succinctly captured by Jegede (2000:14):

Although these classical areas shall continue to be taught, there is need to include new areas in order to meet the challenges of the modern world and technology. It is important to make anthropological training computer-based so that it can meet new challenges. Also training in vocational practice and transferable skills should be offered in order to make the discipline available to many at all levels.

\section{Attitudes of Students to the Study of Anthropology}

Anthropology, like most other social science disciplines in Nigeria, has been impacted negatively by the structural problems of the Nigerian state. Prominent among these problems is the massive increase in graduate unemployment since the mid 1980s which has led the government to openly canvass for and initiate programmes in favour of the so-called professional courses in the universities. The sponsoring of a mindset by government that the only way to beat the unemployment trap is to choose science or professional courses in the university have undermined the growth of other disciplines and in the case of anthropology led to a serious decline in student enrolment. Reinforcing this has been the advent of economic adjustments and reforms starting from the 1986 adoption of the SAP in Nigeria which severely limited the financing of public universities.

The outcome of these factors has been the gross decline of productive scholarship, decaying infrastructure and the unpopularity of anthropology and other social sciences/humanities disciplines seen as now tangential to the economic survival of the average Nigerian student. The view of students in this case is consistent with that fact that anthropology has refused to shed its extreme-datedness. In the opinion of Jegede (2000), anthropology is sometimes considered an archaic discipline with no place in the current dispensation because it studies small scale or primitive societies as British Anthropologists are wont to refer to it. But more crucially, the neglect involved in the above structural issues has had far reaching consequences for both anthropology and social sciences as a whole. Particularly, "social science scholars face deplorable socioeconomic conditions both on personal and institutional levels. Academic staffs are grossly underpaid while tertiary institutions suffer a dearth of physical capital urgently needed for maintenance and service provision" (Anugwom, 2004:409). This situation is still largely the same today and 
the scramble among the political leaders to establish private universities has not helped the plight of the public universities in this regard.

The ultimate outcome of a government policy on discrediting the relevance of the social sciences ${ }^{5}$ as it were has had very adverse affect on the preference of students for anthropology at the tertiary level. This much was revealed by our study of students' course preferences in tertiary institutions in Nigeria. The study took a sample of 200 students in their penultimate and final years in four universities offering the BSc sociology/anthropology degree ${ }^{6}$ and sought to discover their preferences, views and attitudes to anthropology as a discipline. Surprisingly, only 12 of the students or $6 \%$ of the entire sample chose anthropology as their preference over sociology. This is really a very abysmal proportion and hence we decided to find out from both sets of students why their preferences. Their typical responses are summarised in the table below:

Table 3: Reasons for Studying and Not Studying Anthropology

Students who prefer
Anthropology

1. Anthropology studies the human culture, belief systems and norms in the society;

2. I am curious to know more about the lives of the people in the rural areas and their cultural artefacts;

3. It is in line with my vision to promote youth rights and empowerment from the background of their cultural heritage;

4. I believe that culture is important to development.
Students who would not prefer Anthropology study

1. Anthropology is a primitive and abstract discipline;

2. Anthropology is so abstract and makes us believe things we cannot see;

3. Anthropology deals with the past which makes it uninteresting;

4. Anthropology talks about ancient things one cannot imagine or configure correctly;

5. I would not like to be idle and unemployed after graduation.

The point from the above table is that after so many years anthropology is still largely a misunderstood discipline even amongst students who ought to know better given that they are in sociology/anthropology departments. Equally interesting is that the fear of unemployment is a major 
concern for students in deciding preferences, anthropology is seen by the students as largely irrelevant to their aspirations towards gainful employment after graduation.

The obvious apathy of students towards the discipline is quite understandable in view of the employment and career driven nature of today's tertiary education, especially in a developing nation like Nigeria. Perhaps anthropology, just like a good number of other social sciences disciplines in order to capture the interests of a good number of students needs serious and dynamic retooling and refocusing. In this regard, one agrees with the submission that there is need for, "a continental network of anthropologists concerned with the development of new methods of teaching and learning which are working to equip students with the disciplinary and transferable skills - analytical, organizational and practical - needed for employment outside academics" (Jegede, 2000:10).

\section{Anthropology and Social Development in Nigeria}

Anthropology is a form of knowledge pursuit that is imperatively linked to both the survival and development of the society since it focuses on human beings, their societies and the mechanisms or strategies evolved by humans in order to adapt to the multiple challenges of their environment (see Anugwom, 2004). In this sense, anthropology as a discipline have both theoretical and practical contents that ultimately affect development. Perhaps nowhere is this more apparent than in today's society in which the need to adapt development programmes and goals to the needs and aspirations of the people has become overwhelming.

One shortfall of anthropology in Nigeria, which has been made sharper by the development crisis facing the country, is the ambiguous connection between the discipline or its outcomes and the development needs of the country. In this sense, anthropology as presently studied in Nigeria approximates knowledge for knowledge sake than a process that can generate development options. However, the emergence of anthropology as a knowledge base for development intervention by development agencies implies that this shortcoming is a product of both the visionary impediments of these policy makers and the handicaps of the scholars of anthropology in Nigeria.

Anthropology is concerned with the diverse socio-cultural heritages and practices that have served as the basis of people's existence on earth (see Anugwom, 2000). This places anthropology at a critical position in social development since it provides what may be considered holistic and encompassing knowledge about man and his society. But as a disci- 
pline, especially in a developing society like Nigeria, the lofty and ambitious aim of anthropology to provide explanations for all facets of life has generated epistemological problems in the discipline. Part of this problem has been the dilemma of distinguishing anthropology and its methodologies from those of other related disciplines, especially if anthropology is genuinely cast as a concern with both developing and developed societies of the world (a view that appeals to African scholarship). But even more critical is the issue of opposing or competing approaches and orientations among anthropologists themselves. For instance, while most British Anthropologists and by implication Nigerian anthropologists would see themselves as doing social or cultural anthropology and invariably defining it as the relevant domain of modern anthropology, others would either see themselves as total anthropologists or not belabour the distinction between the physical and social. This problem is a significant one in Nigeria's tertiary institutions where the anthropology offered by first generation universities differs from one institution to another in some respects.

While the British legacy of anthropology, especially in terms of nomenclature and its domain as a social science discipline subsists, a classical British approach to the study of the discipline which usually emphasises social discontinuities or the differentiating of each social group from another would be counter-productive in Nigeria's quest for development. Therefore, instead of studying societies in Nigeria as isolated groups or emphasising distinctive features in these societies and using them to mark differences or uniqueness, ${ }^{7}$ there is need for a more integrative approach which while identifying differences emphasises uniformities and commonness.

But beyond a mere focus on the practical utility of anthropology, its existence as the core of the social science knowledge in Africa and elsewhere has implications for development. The impact of the above statement can be appreciated against the contention of the World Bank (1999:25) that "successful development entails more than investing in physical capital or closing the gap in capital. It also entails acquiring and using knowledge - closing the gaps in knowledge". Actually if anthropology has more obvious relevance in developing societies as the classical literature suggests, then the need for anthropological knowledge in Africa cannot be over-emphasised. Perhaps the development doldrums in which Nigeria finds itself despite massive human, material and mineral resources may be linked to the underdevelopment of anthropology in the country. 


\section{Constraints and Challenges}

The 'bad' name, which still shadows anthropology today, derives from its usage in the colonial enterprise. Such utterances (in reference to anthropology) like 'the hand maiden of colonial governments' or 'child of imperialism' (see, Gough, 1966; Hooker, 1963 in Otite, 1997) and even the more provocative dubbing of anthropology "that bastard and illegitimate union of the academic profession and the colonial administration" (Ladimeji, 1972:16) amply underline the negative impact of the colonial role of anthropology on the perception of the discipline especially by Africans.

In spite of this, one critical factor that has militated against the growth of African anthropology has been the lack of courage of African anthropologists, unlike their European and American counterparts, to understand the study of societies entirely different and not in any way contiguous to their own. While this fact can be partially blamed on structural problems with roots in the African university system, anthropologists have equally opted to study societies that are in reality their own pseudosocieties or societies contiguous to their societies.

This lack of courage to face the unknown or confront the unpredictable has meant ultimately a stifling of the space for knowledge growth. Some anthropologists in Nigeria have often studied societies that are theirs or less than thirty kilometres from theirs and which, by implication, share so many cultural practices or commonalities with their own societies. The fact of cultural uniformity and geographical contiguity invariably limits the scope for the emergence of the new and lead to the production of knowledge which, in its bare, is a smart rehash of what is familiar or an elaborate over-estimation and narration of minor differences (differences in degree than substance). Such tendency to settle for the familiar or to stick as close to home as possible has often warranted criticisms of African anthropology even from the so-called uninitiated or more crucially has confined African anthropology to the passenger seat in the world vehicle of anthropology. A particular indication of this fact is that a good number of African anthropologists are dialect speakers or specialists rather than proficiency in a foreign or different language which classically defines anthropological research.

A very important tool in the development of teaching and research in any discipline is the existence of reliable and peer reviewed journals for the dissemination of research results and forum for exchange and interchange of ideas. Incidentally, in spite of the number of tertiary institutions offering anthropology in Nigeria, there does not exist even one good 
journal of anthropology in the mode of the American "Current Anthropology", "American Anthropologist", the British "Man", "Anthropology Today" or even closer to home the good number of related journals in South Africa. ${ }^{8}$ Even the attempt through the years to have a journal of Sociology and Anthropology has been epileptic and un-sustained. This major lapse has limited the ability of Nigerian anthropologists to avail themselves of the opportunity of a unique professional journal for dissemination of research outcomes. While this issue may not be directly related to the prevailing research, lethargy in the profession in the country, it is a fact that the existence of easily accessible outlets for research output encourages research since the major aim of research is publication. ${ }^{9}$ In other words, this has meant the inability of Nigerian anthropologists to produce ethnographies and articles that would define, sharpen and structure the discipline, thereby making Nigerian anthropology simply a matter of following the course charted by the early Western scholars.

Obviously, the dearth of research opportunities and a self-inflicted academic timidity has created a scenario whereby African anthropologists now attempt merely to play catch-up. In other words, Africans have even conceded the lead role in the study of anthropology of Africa to Euro-American scholars whose control of the more influential academic knowledge dissemination channels have had a field day narrating the stories of Africa and Africans even in the present context of a highly developed knowledge environment in the continent. It is, of course, not prophetic to state that this academic dominance has created an 'other' perspective to anthropological narratives that often do not represent or capture entirely the reality. This form of narration may not be the norm, as it were or produced always by deliberate slanting or economy with the truth, but rather typifies the fact that no one tells the story better than those involved.

There is also the problem of the lack of a databank on professional anthropologists in Nigeria and this has negatively impacted on the collegiate atmosphere of exchange and discourse necessary for professional growth and affected the public awareness of the contributions of the profession to national development efforts. More telling, however, is the inability of Nigerian Anthropologists to develop a distinct character, a problem that is actually general in the social sciences. In fact, the overt domination of the social sciences by Western ideals, values and ethics have not helped the affinity of such disciplines to development in the African context (Anugwom, 2004). This is nowhere more typical than in Nigeria. 
Interestingly, some Nigerian scholars have seen the problem of anthropology as emanating from its association with sociology in the academic circles in the country. For instance, Ogundipe (1992) locates the bane of anthropological studies as lying in its playing subservient and obscure roles vis-à-vis sociology. The fact is that in many Nigerian tertiary institutions, as our table has already shown anthropology is conceived as addendum of sociology. In fact, the label 'Department of Sociology and Anthropology' or even 'Sociology/Social Anthropology' underlines this practice which has relegated anthropology to the background in terms of resource allocation and even attraction to students. While this practice may be seen as really not very harmful at the undergraduate level, its impact is well felt at the post-graduate level where sociology thoroughly dominates. For instance, the post-graduate enrolment in Anthropology in one of these universities presents the picture clearly:

Table 4: Average Figure of Post-Graduate Enrolment in Anthropology in University of Nigeria, Nsukka $(1998-2006)^{*}$

\begin{tabular}{lc}
\hline Period & No. of Students \\
\hline $1998-2003$ & 1 \\
$2003-2004$ & 2 \\
$2004-2006$ & 5 \\
\hline
\end{tabular}

Source: Estimated from Post Graduate Records (1998 - 2007),

Department of Sociology/Anthropology, University of Nigeria, Nsukka

* Though the data relates to Nsukka alone, the chance of a radical positive difference in other institutions is slim.

\section{Charting a Way Forward}

Basically the problems bedevilling both the teaching and researching of anthropology in Nigerian tertiary institutions can be seen as resulting mainly from the colonial identity of the discipline and the structural underdevelopment of the Nigerian educational system cum the entire socio-economic structure as well as the incapacity of Nigerian Anthropologists. As a result, Nigerian anthropology has faced a perpetual problem of credibility since its aiding of colonialism has implanted an imagery of an intellectual bid to denigrate indigenous cultures and peoples in the minds of people of the country. Perhaps the inability of the emer- 
gent Nigerian anthropologists to shed the discipline of this toga and make it emerge from behind the clouds created a scenario whereby these anthropologists hid in ivory towers and ministered anthropology to a select few. Incidentally, this bred an unfortunate tendency to see anthropology as an esoteric undertaking with limited bearing on development needs of the people. Without doubt, in the last two decades there has been significant attempts by a few Nigerian anthropologists to properly define and redefine the Nigerian vis-à-vis other peoples and cultures of the world.

However, such attempts have appeared too far in-between and too little. Moreover, such attempts have been undermined by the inability of the Nigerian anthropologists to offer an authentic and different discourse. We have remained content with a submission to the disciplinary borders drawn by Euro-American scholars. This in the views of Prah (1992) creates a situation where the intellectuals of anthropology in Africa have established no tradition worth the name but are content to operate as simply 'local correspondents' for Western intellectuals. Probably, this is in spite of the thinking in some quarters that some theories in the discipline serve to justify and rationalise the exploitation and domination of the developing nations.

Therefore, the challenge before the Nigerian Anthropologist is much the same challenge facing African Anthropologists in general. However, the start point of facing this challenge is to interrogate the imageries of Africa created by the 'other'. Undoubtedly, Anthropologists have played a huge role in the definition of what is African or 'Africanness' today. This is a crucial challenge which African Anthropologists should tackle with candour in order to ensure that such imageries of Africa represent the authentic African reality. A challenge made incontrovertible by a realization that much of what is African today is so un-African (see, Otite, 1997) and calls for a continuous effort on remaking such imageries of Africa purveyed by Western Anthropology. This means equally giving anthropology education authentic African social and cultural roots, as one sure way of tackling the alienating influence often associated with Western education which is a major departure from the socio-cultural context of pre-colonial education.

According to Anugwom (2004:406), "education in the context of the pre-colonial African society was structured by and made relevant to the socio-cultural realities of the societies concerned". This was hardly the case of anthropology since it first assumed the toga of a legitimising narrative by colonial missionaries, bureaucrats and journeymen who 
sought to validate the absurd claim of colonialism as a civilising mission. Unfortunately, these journeymen took the stage before the pioneer pre-colonial western anthropologists who studied Africa genuinely. Probably, the origin of anthropology within the context of the conniving repertories of the journeymen from Europe had far reaching implications for the acceptance and growth of the discipline in Nigeria. In other words, anthropology began as imagery of the colonial overlords and in all essence a largely counter-narrative of the indigenes of the country. Hence the challenge of anthropology after colonialism has been to reverse the above notion. Perhaps, the inability of anthropology to still command a large following especially among students may be related to the original impact of the colonial encounter. Indeed anthropology, as other social sciences, came to Nigeria during the colonial era and in the garb of colonialism (see, Lerche, 1981). But the crucial difference between anthropology and the other social sciences in terms of the colonial contact is that anthropology was initially used for the exclusionary depiction of Nigerian peoples as backward upon which the enterprise of colonialism was justified.

Definitely, anthropology in Nigeria has borrowed quite a lot from the British tradition, though the existence of other influences and approaches cannot be denied. In view of this, there is need for the development of authentic Nigerian anthropology which would do away with the study of Nigerian peoples and societies as 'distanced others'. In other words, a more insider and integrative approach is needed.

\section{Conclusion}

In consonance with the foregoing, the bid to give anthropology a fitting status in both academic and development discourse in Nigeria calls for some systematic advocacy. There is, thus, need for advocacy by anthropologists as a way of raising the popularity of the discipline and the establishment of a strategic plan which focuses on institutional strengthening of universities to teach anthropology, dynamic cultural curriculum, research and dissemination channels, and professional values and bonding.

While the above gives us the general picture, there are still a few Nigerian anthropologists who are into research concerns that are indeed in tune with contemporary needs of society while still remaining undoubtedly anthropological in orientation and methodology. In this sense, these scholars are in two main categories: those who while conscious of classic anthropological methods, adapt these to the realities of 
contemporary plural society by seeing culture as mediating man's lived experience in today's world; and those who focus on narrow ethnographic concerns or what one such anthropologist labelled a holistic study of groups with no extant ethnographies. ${ }^{10}$ Despite the above, these approaches are yet to significantly affect the teaching of anthropology or the curriculum especially at the undergraduate level.

In spite of all deficiencies pointed out, anthropology is without doubt relevant within the context of Nigeria's development. The utility of the discipline's quest to offer a proper understanding and projection of the Nigerian reality cannot be over-emphasised in the country's march to development. Fortunately enough, Otite (1997) argues that African anthropology and Anthropologists can acquire worthwhile relevance by unravelling the African society, its structure and functions, the relationship between its units and the place of the supernatural element in the human development cycle. The above clearly illuminates one path of relevance that may be towed by Nigerian Anthropologists. Despite its undoubted value, Nigerian anthropology faces the critical challenge of carving out a resilient socio-cultural imagery of Nigeria with definite theoretical and practical dimensions. This is only possible through a robust research in the discipline and a teaching curriculum which while pandering to theoretical and methodological rigours, take on board the dynamics of present day Nigerian society. This would perhaps make the teaching of the discipline interesting and do away with the allegations of being abstract which students level against the discipline.

It has been suggested that, "in order to enhance teaching skills, there is need for national discipline - specific training programmes which would equip teachers with expertise specifically in the teaching of anthropology. Anthropology teachers should be reflective practitioners who should regard their experiments in teaching as action research" (Jegede, 2000:14). This approach, apart from giving anthropology a much needed professional touch, would ensure an education rooted in the development needs of the receivers of such education. Therefore, it is only through a focus defined by the above needs that Nigerian anthropology can offer valuable perspectives on the unending crisis of development in the country and in the process enable a culture mediated understanding and resolution of Nigeria's developmental problems. 


\section{Notes}

1. Anthropology as used in this discussion refers to cultural or social anthropology as distinct from physical or biological anthropology

2. The situation in almost all Nigerian universities.

3. As Jegede (2000) infers, the growth of anthropology has remained very slow in Africa, compared with other social science disciplines.

4. For instance, in the University of Nigeria, Nsukka for over twenty years now only three heads of department have been anthropologists and currently of about seventeen lecturers in the department only four are anthropologists.

5. Actually Nigeria's former President Olusegun Obasanjo (1999 - 2007) was once reported as telling newsmen during his tenure that those who studied mass communication, sociology, anthropology and other related courses deserve no employment in Nigeria, since such courses are not relevant.

6. The universities are University of Nigeria, Nsukka; Nnamdi Azikiwe University, Awka; Ebonyi State University, Abakaliki; Benue State University, Makurdi. The interviews took place between July 3 and 24, 2007.

7. One needs to think about the ethnographies of such icons of the British approach like Malinouski and Evans-Pritchard who viewed society as existing in equilibrium.

8. For instance, Social Dynamics; Journal of Southern African Studies; Bantu Studies (now African Studies).

9. A problem made worse by the still debatable existence of gatekeepers and gatekeeping mentality which severely limits the access of African scholars to Western journals even in anthropology where quite a good number of the focus of anthropology research worldwide has been in the African continent

10. Personal Interview, 26-07-2007.

\section{References}

Akiwowo, A., 1976, "The Role of the Social Scientists in Africa", The International Social Science Journal, 28; 1: 198 - 201.

Anugwom, E.E., 2004, "African Social Sciences and Development in the New Century: Challenges and Prospects", African Development Review, Vol. 16; No.2: 399 - 414.

Anugwom, E.E., 2000, "Anthropology: Meaning, Scope and Relevance in Africa", in E.E., Anugwom; V.I Okeke; R.C. Asogwa and Obasi, I.N., (eds), The Social Sciences: Issues and Perspectives, Nsukka: Fulladu Pub.

Diop, M.C., 1992, "Report on CODESRIA's Workshop on Anthropology in Africa: Past, Present and New Visions", CODESRIA Bulletin, 3:1-5.

Ember, C.R. and Ember, M., 1977, Cultural Anthropology, New Jersey: Prentice-Hall. 
Goldthorpe, J.E., 1985, An Introduction to Sociology, Cambridge: Cambridge University Press.

Jegede, A.S., 2000, "From Gateway to Gatekeeper: Anthropology: Yesterday, today and tomorrow", In P. Nkwi (ed.), The Anthropology of Africa: Challenges for the 21 $21^{\text {st }}$ Century, Proceedings of the $9^{\text {th }}$ Annual Conference of the Pan African Anthropological Association (30 August $-2^{\text {nd }}$ September). Yaoundé, Cameroon: ICASSRT Monograph 2.

Ladimeji, O.A., 1972, "Philosophy and the Third World". Radical Philosophy, 3: $16-18$.

Lerche, C.O., 1981, "Social Science and Society in Contemporary Nigeria", in A.O. Sanda (ed.), Social Science and Social Policy in Nigeria, Ibadan: NISER.

Mafeje, A., 1996, "A Commentary on Anthropology and Africa", CODESRIA Bulletin, No. 2; Dakar: CODESRIA.

Ogundipe, A., 1992, "Roots, Relevance, Reinvention: the emergence of African anthropology", Paper presented at the Workshop on Anthropology in Africa: Past, Present and New Visions, Dakar, Senegal, Nov. $11-13$.

Otite, O., 1997, "Rediscovering Anthropology as an Instrument of Development in Africa". Keynote Address presented at the 1997 Conference of the Pan-African Association of Anthropologists, University of Ghana, Legon 8 - 12 September, 1997.

Prah, K.P., 1992, "Anthropology in Africa: Past, Present and New Visions". CODESRIA Bulletin 3: 11 - 15.

World Bank, 1995, World Development Report: Knowledge for Development, New York: Oxford University Press. 